\title{
An Assessment of the land use and land cover changes in Shurugwi district Zimbabwe 1 Matsa Mark and ${ }^{2}$ Muringaniza Kudakwashe \\ doi: 10.4314/ejesm.v4i1.10
}

\begin{abstract}
Zimbabwe's fast-track land reform programme and other economic activities have caused considerable land cover /land use changes to the country's ecological environment and Shurugwi district has been no exception. Most of these changes are yet to be captured and documented as essential baseline information for developmental purposes. This paper seeks to establish the current status of land use and land cover changes for Shurugwi district as well as to determine the extent of these changes using Geographic Information System and remote sensing techniques. Three satellite images for three different years (1991, 2000 and 2009) were used to come up with a land use/land cover map classification for Shurugwi district. Image processing and image classification were done in order to establish the land use /land cover of the district. To determine the extent of land use/land cover changes in the district between 1990 and 2009 Landsat images of the district were downloaded from the Global Land cover Facility as well as from Google Earth Image Domain. The images were analysed using change detection techniques along with Google Earth screen to screen images to come up with the extent of the changes that have occurred. Results show that cultivation and bare land dominate land use/land cover for the district at $53.4 \%$ while degraded land covers $26.6 \%$ with the rest shared between vegetation (18.1\%) and water (2\%). There has been considerable land use/land cover change in Shurugwi district between 1990 and 2009. The greatest change occurred to vegetation which experienced a 9.4\% decrease between 1991 and 2000 and an even higher decrease of 11.6\% between 2000 and 2009. The study recommends that government concludes its land reform and resettlement programme to reduce continued ecological destruction. The Environmental Management Agency should also educate newly resettled farmers and other stakeholders like miners (including gold panners) on the need for proper environmental management essential for sustainable development.
\end{abstract}

Key terms: Geographic Information System, Remote Sensing, Fast-Track Land Reform Programme, Satellite images.

\section{Introduction}

Studies have shown that there Sremain only a few landscapes on

Earth which are currently in their natural state. Due to anthropogenic activities, the Earth' surface is being significantly altered and the presence on the Earth of man and his use of land has had a profound effect upon the natural environment (Wilkie and Finn, 1996; Briney, 2008). As a result since the early 1980 s vast transformations have occurred in the land use and land cover patterns as evidenced by persistent expansion in cultivated land, decrease in natural woodland and grassland in the world (Zonneveld 1979; Miller, 1996; Xiaomei and Ronqing, 1999).It can therefore be stated that the land use and land cover pattern of a region is an outcome of natural and socio-economic factors and their utilization by man in time and space.

Viewing the Earth from space is now crucial to the understanding of the influence of man's activities on his natural resource base over time. In situations of rapid and often undocumented and unrecorded land use change, observations of the earth from space provide objective information of human activities and utilization of the landscape. Over the past years, data from Earth sensing satellites has become vital in mapping the Earth's features and infrastructures, managing natural resources and studying environmental change.

Remote Sensing (RS) and Geographic Information System (GIS) are now providing new tools for advanced ecosystem management, land use mapping and planning. The collection of remotely sensed data facilitates the synoptic analyses of Earth system functions, patterning, and change at local, regional as well as at global scales over time (Lambin and Strahler, 1994; Lambin et al, 2001 Lambin et al, 2007). Such data provides an important link between intensive localized ecological researches, regional, national and international conservation and management of biological diversity (Wilkie and Finn, 1996).

GIS is a valuable tool to better manage, interpret and maintain resources. It is a proven decision support system employing land cover change maps among other data resources that are major products created from remotely sensed data (Paule et al, 2001; Lambin et al, 2003; Lambin et al, 2007). Keeping track of change is important to our

\footnotetext{
${ }^{1,2}$ Department of Geography \& Environmental Science, Midlands State University, Gweru. Zimbabwe
} matsam@msu.ac.zw; muringanizak@msu.ac.zw 
understanding of the earth as a system. Knowing about those changes is the first step towards understanding why and where they are happening. Change data can be used to update maps, and to estimate the rate of change in certain areas.

In Zimbabwe land is becoming a scarce resource due to immense agricultural and demographic pressure (Chenje et al 1998; Tomlinson, 2006).This is especially so given the government's controversial Fast-Track Land Reform and Resettlement Programme (2000-2009) which saw a significant number of black farmers 'invading' formerly whiteowned farmland which to a large extent had pristine vegetation and natural ecosystems. It is against this background that this paper seeks to establish the current status of the land use and land cover for Shurugwi district as well as to determine the extent of these land use and land cover changes in the district between 1990 and 2009.

This is because no attempts have so far been made to document the dynamics of land use and land cover using GIS and remote sensing for the district with reference to the nature, magnitude; rate and extent of land use and land cover changes (Matsa and Muringaniza, 2010). Remote sensing and GIS in this research has the advantage that it provides a general extensive synoptic coverage of large areas and possesses powerful capabilities with evaluation techniques for detected changes. Satellite imagery is also suitable to study changes in unhospitable and inaccessible terrain and helps avoid the high costs for field surveying.

The study is significant as it provides a new dimension to land use and land cover studies in Shurugwi district by establishing the extent of the changes. This information on land use and land cover and possibilities for their optimal use is essential for the selection, planning and implementation of land use schemes to meet the increasing demands for basic human needs and welfare.

\section{Study Area}

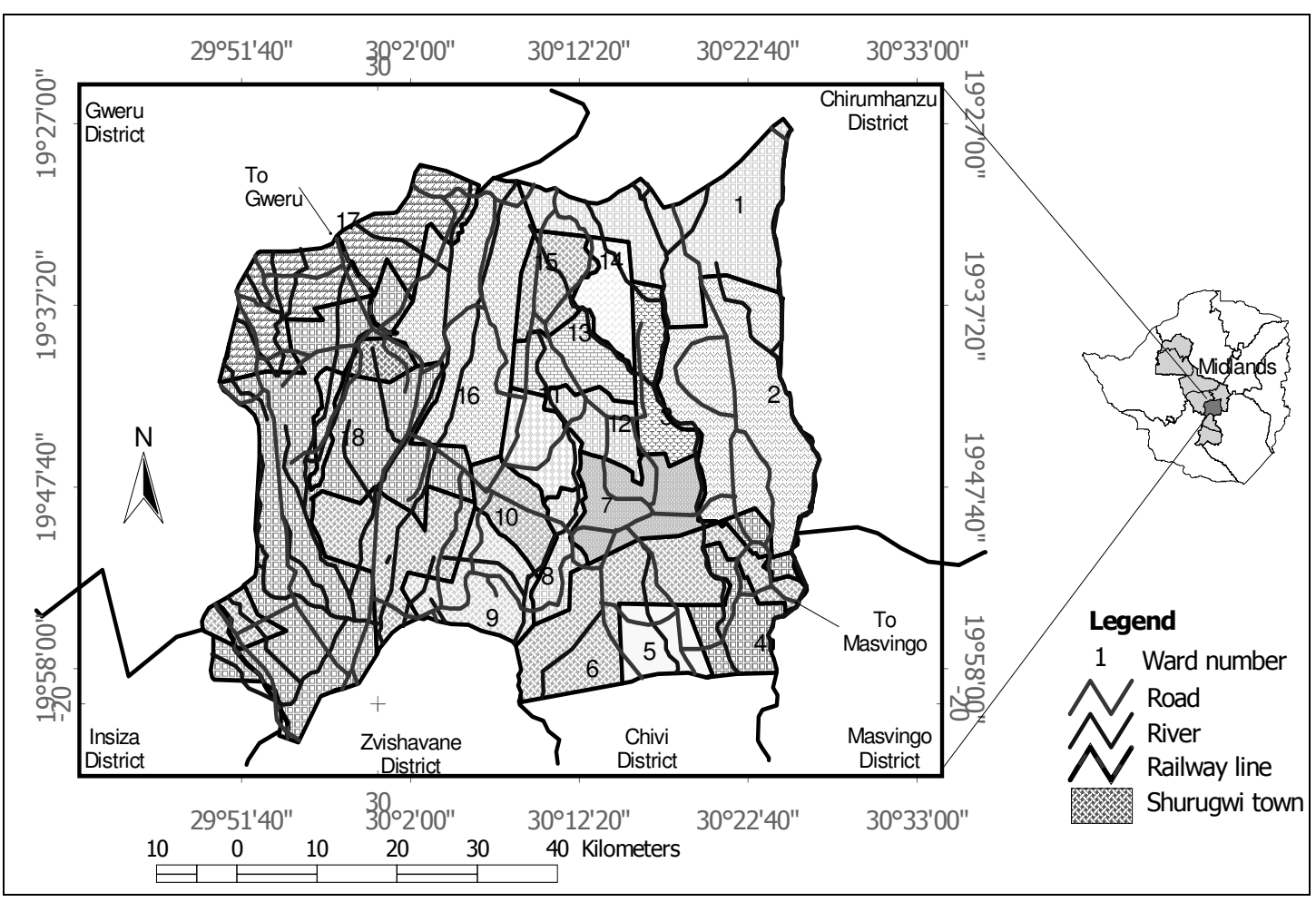

Figure 1: Map of Shurugwi district. 
Shurugwi district is situated about $17 \mathrm{~km}$ to the southeast of Gweru town in the Midlands Province of Zimbabwe as shown in Fig 1. Its altitude is 1501 meters and lies in the time zone of approximately UTZ +2 . Its principal town is also called Shurugwi which was established in 1899 on Selukwe goldfield thus the district remains an important centre for gold, nickel, chrome and platinum mining. The town is located on the mineral rich belt, commonly known as the Great Dyke in Zimbabwe and also on one of the most beautiful (scenic) places in the country, Wolfshall Pass commonly known as Boterekwa. The district lies in agro-ecological region 3 that receives an average rainfall of between $650-800 \mathrm{~mm}$. It is characterised by a number of land uses including residential (settlement), agricultural, mining, industrial and forest areas with the major human activities in the rural areas being subsistence to intensive cropping and animal farming, cattle and goats forming the back bone of the community's wealth (Madebwe and Madebwe, 2005).

There are such service centres in the district as Chachacha (Donga) Rural Service Centre and Tongogara Growth Point (the seat of the Rural District Council). Chachacha is the best located service centre in Shurugwi rural because it is where major roads meet. Unfortunately it has been neglected and the growth point status was placed at Tongogara where it failed to grow because of poor road network and its remote location in relation to other centres of economic activity. There are both commercial and subsistence farmers in the district utilizing land resources of varying proportions based on the Zimbabwean domestic land policy of 1980 and the 2000 land reform that has realised either change of ownership or fragmentation of these farms (Tomlinson, 2006). According to the Central Statistical Office (CSO) report (1992), Shurugwi district had a population of approximately 76138 in 1992 , which grew significantly to 88390 in 2002 (CSO, 2002). This is attributed to the fact that it has evolved as an important centre for gold, platinum and chrome mining. These mining sites are located in the range of $5.2 \mathrm{~km}$ to $33.3 \mathrm{~km}$ from the town centre which is predominantly in the rural areas. Examples include Dunraven $(5.2 \mathrm{~km})$, Railway Blocks $(5.5 \mathrm{~km})$, Tebekwe $(7.6 \mathrm{~km})$, Lulu (17.3km), Selukwe Peak (17.3km), Unki (26.6km), Beste (27.4), Solo (33.3km) and Papyrus (33.3km) (Tomlinson, 2006). There are a number of primary schools in the district such as Vungwi, Banga, Bokai, Chitako, Dombwe, Makonde, Matamba, Nhema (St Francis), Pakame, Wida and Zishazha primary schools among others. There are a number of secondary and high schools such as Mupangai, Chivakanenyaka, Batanai, Rusununguko, Dombotombo and Bokai secondary schools as well as Hanke Adventist, Tongogara and Pakame high schools. In the district are health services offered at hospitals such as Shurugwi hospital, Zvamavande rural hospital, Hanke clinic, St Francis clinic, Tongogara clinic and Gundura clinic.

\section{Methodology}

The study used three satellite images of different years to come up with the land use/ land cover map and classification of Shurugwi district. The two Landsat TM satellite images of the district for the years 1991 and 2000 (path/row 170/74; captured on 17 April 1991 and 23 April 2000 respectively) were obtained from the Global Land cover Facility (GLCF) on Earth Science Data Interface (http://glcf.umiacs.umd.edu.8080/esdi/index/js p) while the third image (October 2009) was obtained from the Google Earth Image Domain.

\section{Establishing the land use and land cover status for Shurugwi district}

The estimation of the current land use and land cover status for the district was done in a series of steps for the 2009 Google Earth image. The satellite image which was obtained from the Google Earth Image domain was captured as a set (series) of screen by screen images; each covering a relatively small area of the district (Figure 2). This was performed in order to capture as much detail as possible relating to fields, streams, roads, vegetated areas, degraded and the bare land. A total of 80 images were captured screen by screen and were saved in JPEG file format as shown in Figure 2.

On completion; each scene was imported and georeferenced in ILWIS 3.4 and ERDAS Imagine 9.1. The georectification was performed according to the Geographic (Latitude/Longitude) projection system (WGS84) on each single image after which all 80 scenes were combined into a mosaic in ERDAS Imagine 9.1. The georectification process for each image used road junctions, 
bridges and clear buildings along with reference to a 1: 250000 topographical map obtained from the Surveyor General. A subset image of Shurugwi district was created by overlaying and masking the image layer with a thematic layer of the district. The subset image was then classified to come up with the land use/ land cover status of the district.

The image classification process involved both supervised and unsupervised classification in order to come up with a current depiction of the state of land use and land cover in the district. The district image was first classified in ENVI into a maximum of 60 unsupervised classes from 10 iterations using the K-Means algorithm (Figure 3). This calculated the initial class means (spectral signature) evenly distributed in the data space and clustered the pixels into the nearest class using a minimum distance technique. On doing so this provided a general overview of the land cover over the district based on spectral signatures which was clumped and sieved into 10 classes general classes based on spectral signature responses. This general classification became useful in the field when ground truthing data was being collected as this acted as a guide. After field observation and collection of ground truthed data using a GPS the supervised classification was done as there was now informed basis to generate training sites.

Five vector layers of vegetation areas (forest areas, grasslands), water bodies, cultivated (farming) land, bare areas and degraded land (wasted) were digitized as training sites for the supervised classification. These provided spectral signatures which guided the classification process as all pixels were assigned to a class in which it fitted into the range of an the identified (training site) land use type. The supervised classification process was verified by the field data and was clearly discernible from the images with the assistance of the Google Earth images Domain which provided the opportunity to manipulate scale and view unclear features much easily.

\section{Land use/ land cover changes in Shurugwi district from 1990 to 2009.}

The downloaded Landsat images were obtained in Tiff picture format thus required spatial reference (coordinates) known as georeferencing (georectification). This was done in ERDAS Imagine 9.1 software in which they were imported and recognised as
'Imagine' files. The two Landsat images were georeferenced by the process of coregistration. The 2009 georeferenced image was assumed as the master image from which the two other Landsat images were coregistered in order to minimise the geometric errors. Since the study involves multitemporal analysis performed on a pixel-by pixel basis, any misregistration would provide erroneous results. The average error was 0.032 pixel all the images.

On completion, the georeferenced images were stacked, that is the bands for each Landsat image were stacked together into a single image having been imported into ENVI 4.2 software. A shapefile (thematic layer) of Shurugwi district that was imported from ArcView 3.2a software was then used to mask and subset the study area of the district from the overall Landsat scene image which covered a much larger area stretching as far off as Insiza district in Matebeleland province. Normalisation of the image was undertaken with respect to the other images and the topographic correction.

As Electromagnetic radiation propagates through the atmosphere it interacts with the atmospheric components such as dust particles, water vapour, and clouds such that their representation of values is distorted. Therefore exactitude of the image was improved through calibration, a process in which the top-of-atmosphere (TOP) signals are converted to band-wise spectral surface reflectance. This process was done because the research was using three multivariate (and multitemporal) images spread over 18years hence these had to be independent of all atmospheric variables. Consequently the images were converted from digital numbers to spectral radiance from which they were converted into feature reflectance which recognises terrestrial reflectance digital below is the equation for converting the DN values.

a) Digital numbers were converted to Radiance $\left(\mathrm{L}_{\mathrm{rad}}\right)$ using equation (1)

$$
\begin{aligned}
& \mathbf{L} \lambda=\left(\mathbf{L}_{\text {MAX }}-\mathbf{L}_{\text {MIN }}\right) / 255 * \mathbf{D N}+\mathbf{L}_{\text {Min }} \\
& \text { Where } \lambda=\text { ETM band number } \\
& \text { L }=\text { at-satellite radiance } \\
& \text { Max } / \text { min }=\text { band specific maximum } \\
& \text { nimum radiance } \\
& \text { DN= Digital number }
\end{aligned}
$$
and minimum radiance

b) At-satellite radiance was converted to surface reflectance using equation (2)

$$
\begin{aligned}
& \mathbf{\rho p}==^{\pi * \mathrm{~L} \lambda * \mathrm{~d} 2} / \text { ESUN } \lambda * \operatorname{COS}(\Theta \mathrm{s})(2) \\
& \text { where } \rho \mathrm{p}=\text { planetary reflectance }
\end{aligned}
$$



aperture

$$
\mathrm{L}_{\lambda}=\text { Spectral radiance at sensor's }
$$

$\operatorname{ESUN}_{\lambda}=$ band dependant mean solar exoatmospheric irradiance

$\Theta \mathrm{s}=$ solar zenith angle

$\mathrm{d}=$ earth-sun distance, in astronomical

units

To achieve the desired results, the three images were classified. The image classification process involved both supervised and unsupervised classification in order to come up with a current depiction of the state of land use and land cover in the district. The three district images were first classified in ENVI each into a maximum of 60 unsupervised classes from 10 iterations using the K-Means algorithm which generated 39 classes. Based on the prior field campaign conducted in collecting ground truthing data the classes were merged into 10 classes.

The supervised classification procedure involved digitising vector layers from the satellite images which provided training sites for the supervised classification. Five vector layers of vegetation areas (forest areas, grasslands), water bodies, cultivated (farming) land, bare areas and degraded land (wasted) were digitized as training sites for the supervised classification. This process was guided by verification of land uses and land cover using field data and the Google Earth Image Domain which provided the opportunity to manipulate scale and view unclear features much clearly.

The images were analysed using change detection techniques along with the Google Earth screen to screen images to come up with the extent of the changes that have occurred. Image differencing of each image's bands (Landsat bands 1, 2, 3, 4, 5, and 7) was done so as to analyse and compare the different images pixel by pixel so as to identify and establish the changes per pixel (being representative of the area as a land unit comprised of homogenous biophysical properties). Prominent changes in the land use/ land cover which were observed were zoomed in so as to clearly discern the extent. In this case the classified digital layers' statistics were analysed facilitating comparative analysis of the image along with statistical comparison of the pixel-to-pixel figures. This brought about the direction of change, nature and magnitude of change detected in the three images of the district.

\section{Results and Discussion \\ Land use and land cover status for Shurugwi district.}

Figure 4 illustrates the land use/ land cover classes produced from the supervised and unsupervised classification process which was wielded in this study. It generated five classes; which are water surfaces, bare surfaces, degraded land, farming (cultivated) land and vegetation areas. It illustrates the land cover and the distribution of the land uses across the district.

The vegetated land is qualified as woody areas, grasslands and forests still in a healthy condition. The bare land represents areas covered with rock outcrops, bare surfaces which are heavily degraded (marginal land). This is mostly because of the fact that there are such geological features as the Great Dyke, rocky outcrops and severely degraded lands due to such activities as mining (which includes panning), agriculture and livestock rearing. Areas classified as water represent water covered surfaces while cultivated areas simply represent all land under cultivation in the district. Degraded land in this case is land that has little vegetation cover and is distinguishable from cultivated land delineable through the spectral signature (responses) of the land.

Table 1 presents figures that represent the statistical area of each land use/ land cover category as of October 2009. There is an even distribution of cultivated areas, bare and degraded land mainly because most degraded lands lie within and/ or adjacent to the croplands. Cultivation land (26.6\%), degraded land $(26.5 \%)$ and bare surfaces (26.8\%) dominate the land cover in the district. Major farming activities are subsistence to semiintensive cropping along with animal farming (mostly cattle and some goats) which is concentrated in the eastern region of the district. This confirms the results of a study by Madebwe and Madebwe (2005) Vegetated areas cover $18.1 \%$ of the entire district. The vegetation type is bush savannah grassland with hyperrania, hypothelia and digitaria as the major grass types with sparsely distributed brachystegia, terminalia and julbernadia tree species. Built up areas have not been classified as a single entity in this study because they are spread across other land uses such that it was difficult to single out their spectral signature. 
Figure 5a illustrates vegetation distribution and density (NDVI) over the district from which it is evident that these three aspects are evenly spread across the area.The NDVI image (Figure 5a) confirms the land cover classes illustrated in Figure 4. High NDVI areas (red spots) indicate healthy vegetation while the blue areas indicate cultivated and degraded land. This is because the Great Dyke separates the mining town of Shurugwi to the west and the crowded and overused communal areas to the east. The western part of the Great Dyke also has the advantage that it constitutes former white commercial farms which were better managed until the onset of the fast-track land reform and resettlement programme in 2000.This region has thus not suffered great degradation as the predominantly communal area to the east.

\section{Extent of land use/ land cover changes in Shurugwi district from 1990 - 2009.}

Figure 6 shows the land use/ land cover maps of Shurugwi district with predominant land use/ land cover types produced from the unsupervised and supervised classification process. There is significant change in the images shown in Figure 6 where the density, spread and distribution of vegetation changes significantly from the year 1991 to 2009. The result of this classification shows considerable changes in the land uses of the district between 1991 and 2009 as shown in Figure 7.

Figure 7 indicates significant change in bare, degraded and vegetated land with the greatest change occurring in vegetated areas where there was a $9.4 \%$ decrease in size (that is of the total district area) between 1991 and 2000. It is significant to note in this respect that the greatest change occurred over the latter period from 2000 to 2009 in which a sharp rate of decrease of $11.6 \%$ was realised. Contrary to that, cultivated areas show a reverse trend to that of vegetation in which a general increase is observed. Figure 7 also shows the relationship existent in the changes that are occurring in between the years as an increase in cultivated land for example initiates a decrease in vegetated areas. In Figure 8 the location and extent of land use/ land cover change that has occurred in Tokwe 1 as depicted in the images is rendered through subimages showing the spatial change that has occurred over the 18 years. The extent of vegetation loss from the year 1991 to 2000 through to 2009 is well illustrated as it is either modified or converted. Vegetation has significantly decreased from the year 1991 to 2009 than any other land use class registering the greatest rate of reduction which has been mostly concentrated in the eastern region of the district. The vegetated areas of Tokwe 1 in Figure 8 have been lost to cultivation which is responsible for degrading the land. This also confirms results of a study by Matsa and Muringaniza(2010) which identified cultivation as a major driver for land cover and land use changes in Shurugwi district. This is illustrated by the increase in degraded land that is highlighted in Figure 8 thus showing a significant relationship in reduction of vegetation and the increase in cultivated and degraded land. Therefore a general trend is observed in the images that cultivation has increased at the expense of vegetation cover. Degraded land, bare surfaces, cultivated areas and water surfaces have generally increased in extent (size) from 1991 through the year 2000 to present. The magnitude of change for these four classes though has been moderate as compared to that of vegetation decrease which has been rapid. Furthermore it should be noted that significant changes in the land use and land cover occurred during the $2000-2009$ period as compared to the $1991-2000$ period.

\section{Conclusions}

Land use and land cover for Shurugwi district show vegetation, cultivated land, bare land as well as degraded land. Degraded land is mainly a result of agriculture and mining activities which include panning. Cultivation and bare land dominate land cover/ land use for the district at $53.4 \%$ while degraded land covers $26.5 \%$ with the rest shared between vegetation $(18.1 \%)$ and water (2\%).Major farming activities in the district include subsistence farming mainly in the communal and new resettlement areas (mainly to the east) as well as intensive commercial farming mainly in the western half of the district.

Vegetation type in the area is mainly bush savanna grassland (hyperrania, hypothelia and digitaria) with scattered tree species including brachystegia, terminalia and julbernadia.

There has been considerable land use/land cover change in Shurugwi district between 1990 and 2009. The most significant of these changes occurred to vegetation which experienced a 9.4\% decrease between 1991 and 2000 and an even higher decrease of 
$11.6 \%$ between 2000 and 2009. These changes can be attributed mainly to the government's controversial fast-track land reform and resettlement programme. This could be the reason why cultivated areas show a reverse trend to that of vegetation as it records a general increase in the same period.

\section{Recommendations}

Based on the findings from this study, it is recommended that,Government finalises the land reform and resettlement programme in

\section{References}

Briney, A. (2008) GIS. An overview. An overview of Geographical Information Systems.

http://geography.about.com/od/geographyinter/ a/gisoverview.htm. (Accessed 25 September 2009)

Chenje, M., Sola, L., and Paleczny, D., (1998) The State of Zimbabwe's Environment 1998.Government of Zimbabwe, Ministry of Mines, Environment and Tourism. Harare.

CSO, (1992) Zimbabwe. Census of Population. 1992. Government Printers, Harare

CSO, (2002) Zimbabwe. Census of Population. 2002. Government Printers, Harare

Lambin, E. F., Turner, B. L., Agbola, S. and Angelsen, A., (2001) The causes of land use and land cover change: moving beyond the myths. Global Environmental Change, 11(4): pp261-69.

Lambin, E. F. Geist, H. and Ellis, E. (2007) Causes of land use and land cover change.

http://eoearth.org/article/causes_of_land-

use and land-cover chang (accessed 24

September 2009)

Lambin, E. F. Geist, H. and Lepers, E. (2003) Dynamics of land use and land cover change in tropical regions. Annual review of Environmental resources, 28: 205-241. order to arrest further wanton clearing of land by newly resettled farmers, the Environmental Management Agency (EMA) should hold workshops at village, ward and district levels to conscientise newly resettled farmers on the importance of proper environmental management essential for sustainable development and EMA should also launch a district tree planting and land reclamation(gully-filling) programme in order to reclaim degraded areas

Lambin, E. F. and Strahler, A. H. (1994) Land cover changes in Sub-Saharan Africa (1982-1991) application of a change index based on remotely sensed surface temperature and vegetation indices at a continental scale. Remote Sensing of Environment 61: pp181- 200.

Madebwe, V. and Madebwe, C., (2005) An exploratory Analysis of the Social, Economic and Environmental Impacts on Wetlands: The case of Shurugwi District, Midlands Province, Zimbabwe. Journal of Applied Sciences Research 1(2): 228-233.

INSInet Publication.

Matsa. and Muringaniza K.,(2010) Rate of Land use and Land cover Changes in Shurugwi District, Zimbabwe: Drivers for Change. Journal of Sustainable Development in Africa(Volume 12,No.3,2010)

Miller, G. T., (1996) Living in the Environment. Principles, Connections and Solutions. Wardsworth. U.K.

Tomlinson, B. (2006) Shurugwi, Zimbabwe page. http://www.fallingrain.com/world/ZI/0/Shurug wi.html. (Accessed 25 September 2009) Wilkie, D.S. and Finn, J.T. (1996) Remote Sensing Imagery for Natural Resources Monitoring. Columbia University Press, New York. Page 295. 
Xiaomei Y and Ronqing L.Q. Y, (1999) Change Detection Based on Remote Sensing Information Model and its Application to Coastal Line of Yellow River Delta - Earth Observation Center, NASDA, China
Zonneveld, I. S. (1979) Land evaluation and land (scape) science. Volume 11.4 of ITC textbook. International Institute of GeoInformation Science and Earth Observations ( ITC) Enschede.

Table 1: Land use/ land cover distribution for Shurugwi district.

\begin{tabular}{|c|c|c|}
\hline Classification category & $\operatorname{Area}\left(\mathrm{Km}^{2}\right)$ & $\%$ of total area \\
\hline Water bodies & 74.92 & 2.0 \\
\hline Vegetated land (forest, grasslands and woodlands & 991.71 & 18.1 \\
\hline Cultivated land & 979.704 & 26.6 \\
\hline Degraded land (wasted) & 668.06 & 26.5 \\
\hline Bare land (fallow, bare rock and bare ground) & 979.70 & 26.8 \\
\hline Total area of the district & 3694.0999 & 100 \\
\hline
\end{tabular}

Source: Primary data (using Quickbird image)

Table 2: Land use/ land cover class change

\begin{tabular}{|l|cc|cc|cc|}
\hline Land use/ land cover class & \multicolumn{2}{|c|}{1991} & \multicolumn{2}{|c|}{$\mathbf{2 0 0 0}$} & \multicolumn{2}{c|}{$\mathbf{2 0 0 9}$} \\
\hline Class & Area & Percentage & Area & Percentage & Area & Percentage \\
Water & 34.43 & $0.9 \%$ & 34.35 & $0.9 \%$ & 74.92 & $2.0 \%$ \\
Bare & 496.97 & $13.5 \%$ & 719.23 & $19.5 \%$ & 991.71 & $26.8 \%$ \\
Degraded & 829.09 & $22.5 \%$ & 917.45 & $24.8 \%$ & 979.704 & $26.5 \%$ \\
Vegetation & 1441.77 & $39.0 \%$ & 1095.98 & $29.6 \%$ & 668.06 & $18.1 \%$ \\
Cultivated & 891.84 & $24.1 \%$ & 927.10 & $25.2 \%$ & 979.70 & $26.6 \%$ \\
\hline
\end{tabular}




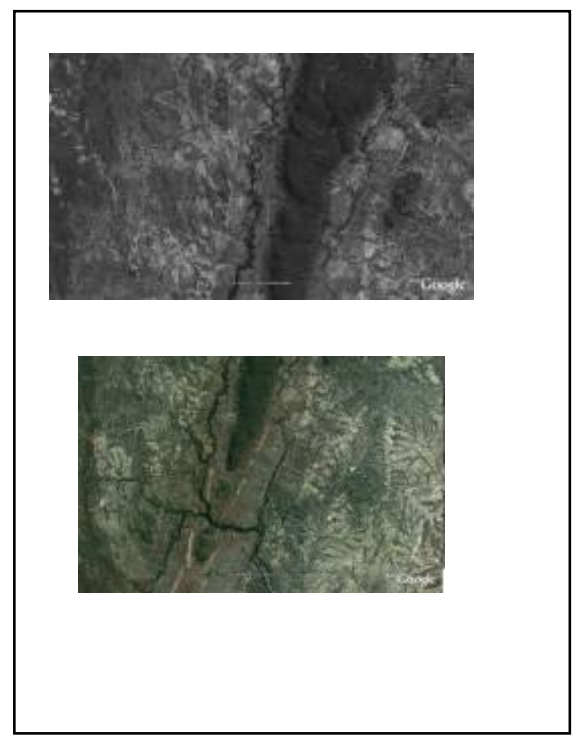

Figure 2: Scenes captured in sequence. (Source: Google Earth Image Domain)

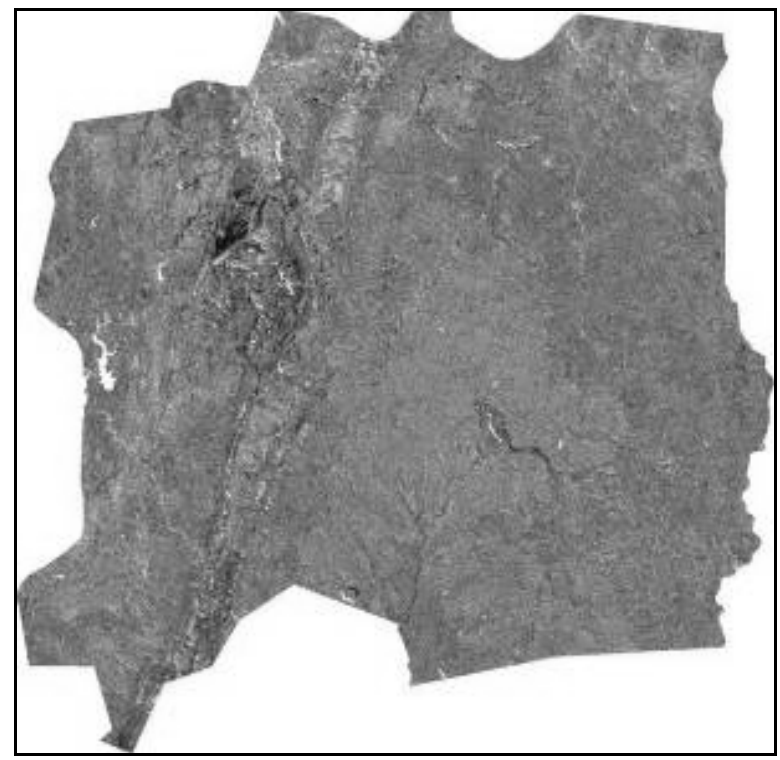

Figure 3: Initial classification process (60 classes). 


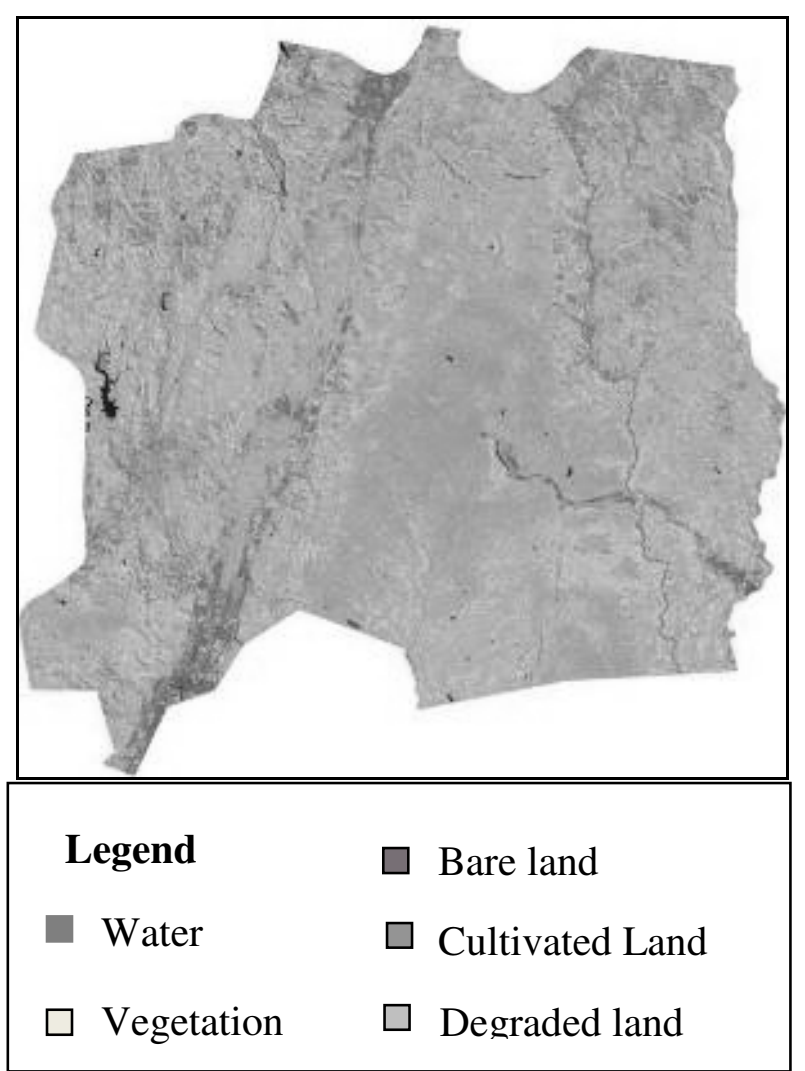

Figure 4: Land use/ land cover status for Shurugwi district
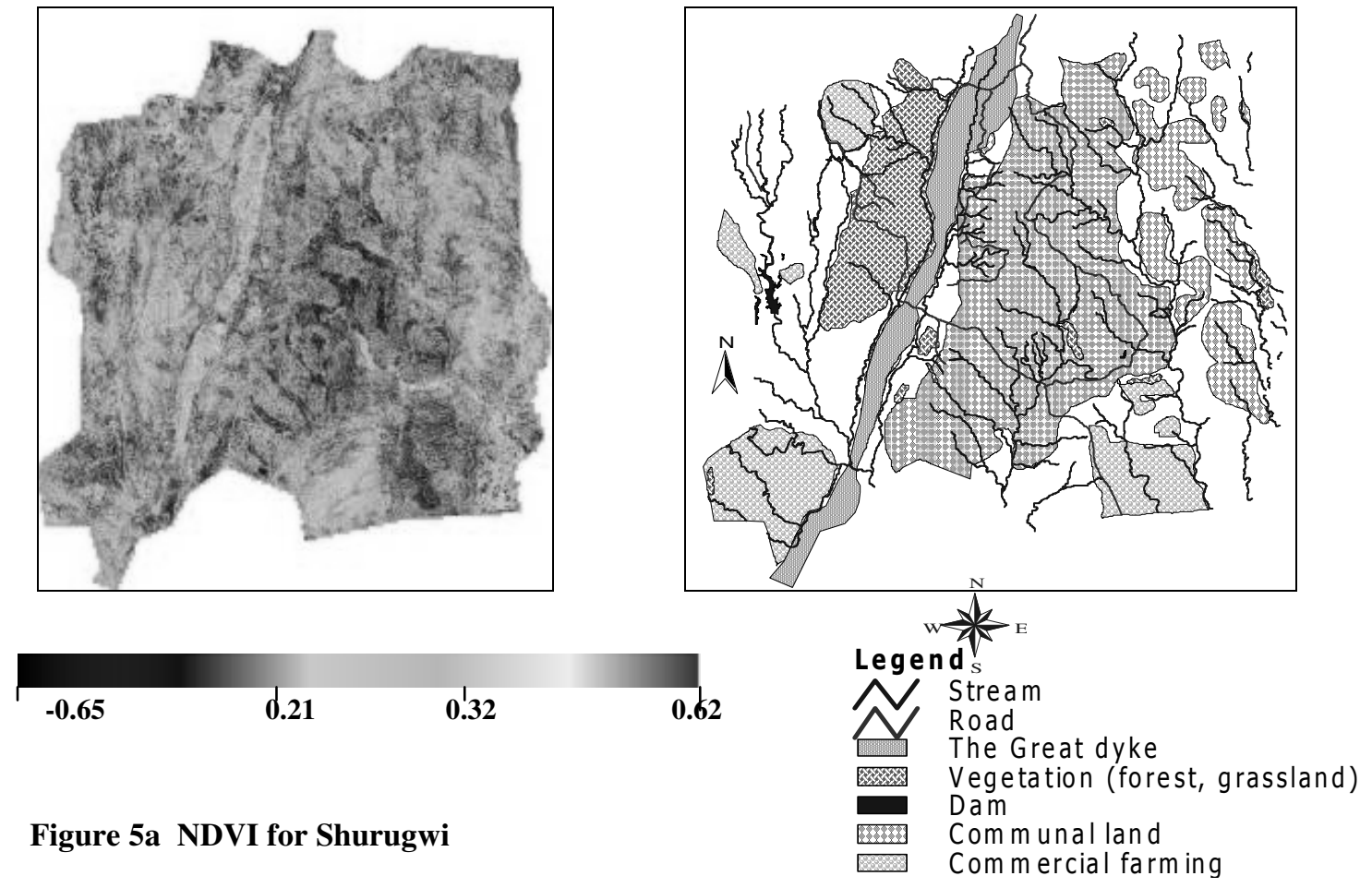

Fig.5b: Major land use/land cover (Shurugwi) 
1991 classification

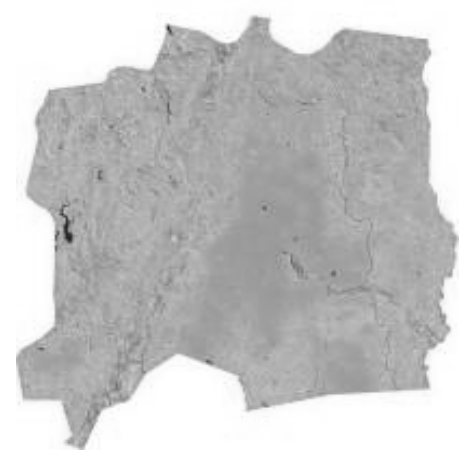

2000 classification

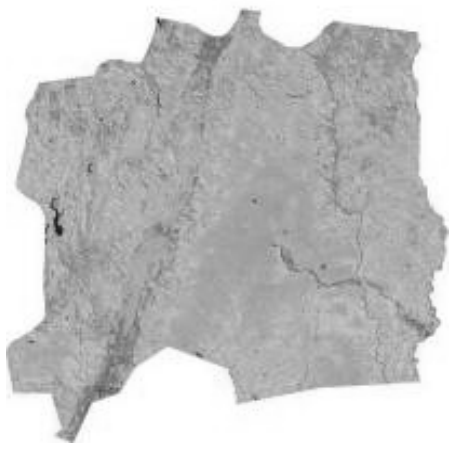

2009 classification

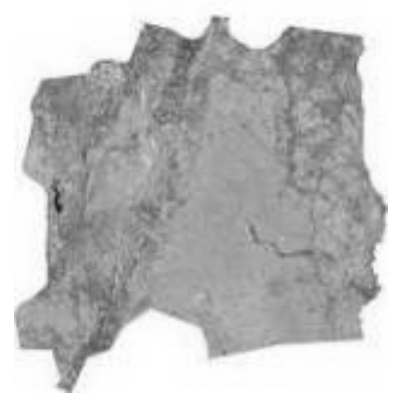

\section{Legend}

Water

Bare land $\square$ Cultivated Land

Degraded land

$\square$ Vegetation sonncu mnages of Shurugwi district

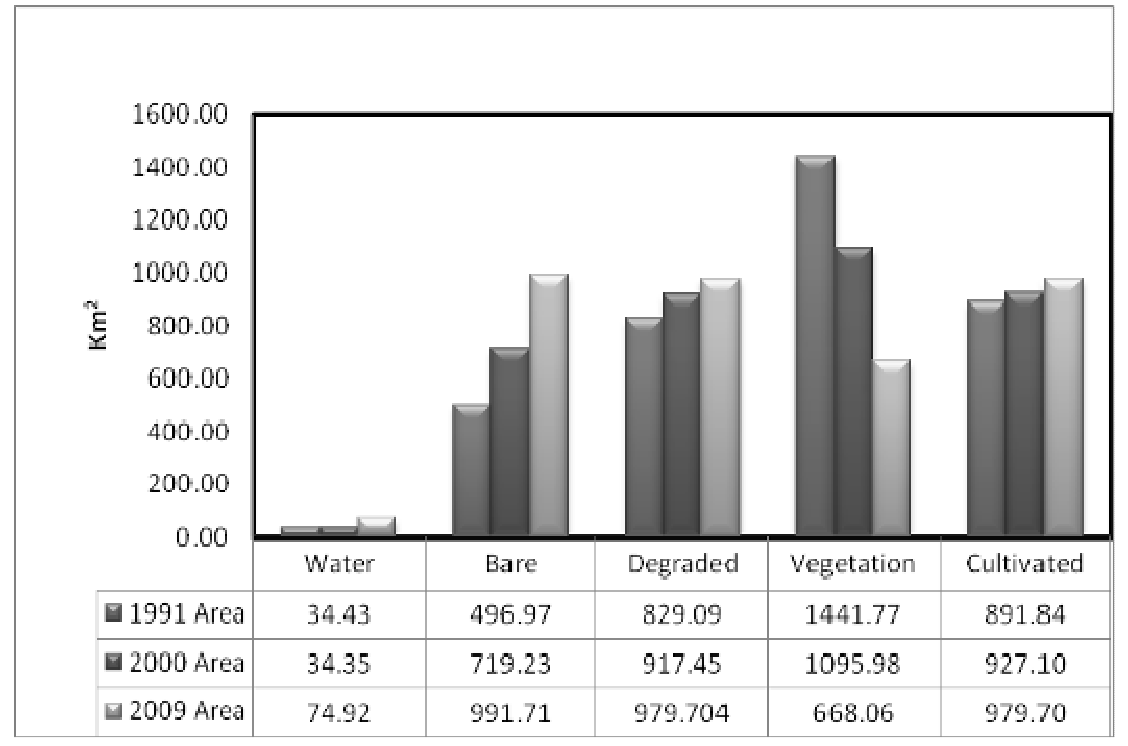

Fig. 7: Land use/ land cover changes over Shurugwi district.

Legend $\square$ Vegetation $\square$ Cultivated Land $\square$ Bare land Degraded land $\quad \square$ Water 
a. 1991 image

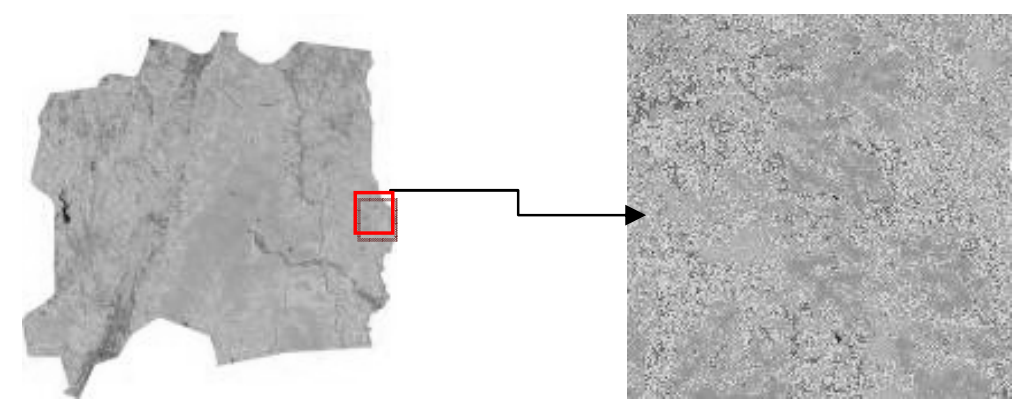

b. 2000 Image

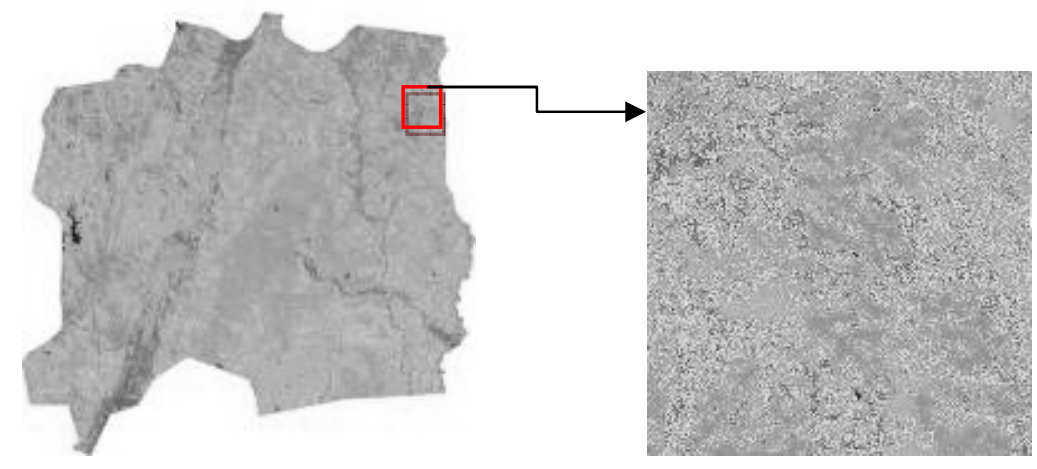

c. 2009 Image

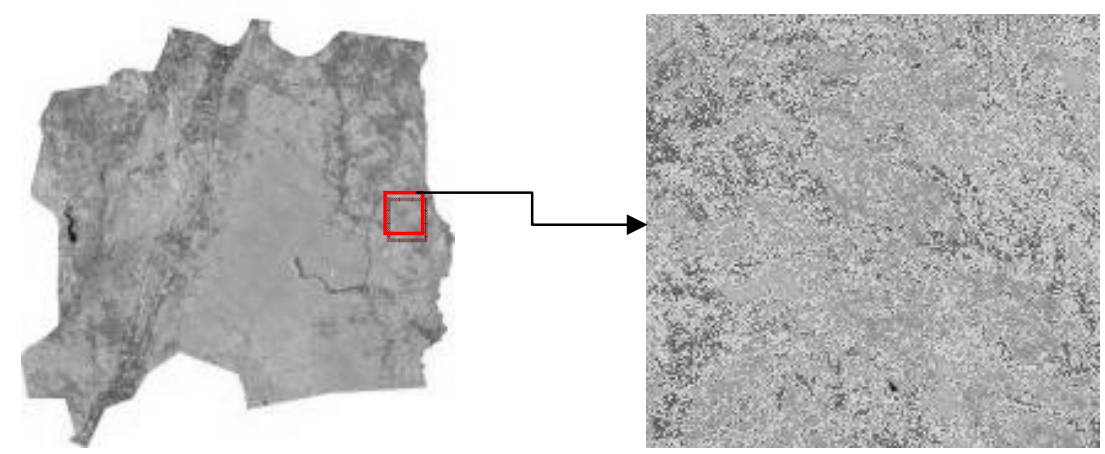

\section{Legend}

Water $\square$ Bare land $\square$ Cultivated Land $\quad \square$ Degraded land $\quad \square$ Vegetation

Figure 8: Land use/ land cover change in Tokwe 1 